\title{
Empirical Evidence Of Verdoorn’s Law In Mexican Manufacturing
}

\author{
Lourdes Alicia González Torres, Universidad Autónoma de Baja California, México \\ Manuel Alejandro Ibarra Cisneros, Universidad Autónoma de Baja California, México \\ Juan Manuel Ocegueda Hernández, Universidad Autónoma de Baja California, México \\ Karla Emilia Cervantes Collado, Universidad Autónoma de Baja California, México
}

\begin{abstract}
In this document we use the model called Verdoorn's Law that has been widely favored with the empirical evidence as being able to explain the persistence of divergences in growth rates, which establishes a positive relation between product growth and productivity. The goal is to estimate the Verdoorn's coefficients for the 32 states in Mexico for the period of 1985-2004 through the use of the Ordinary Least Square method (OLS) and the pool data technique for an added analysis at subsector levels of the manufacturing industry. The purpose of this paper is to explain regional divergences in Mexico by identifying those factors that influence economic growth and that would allow the proposal of regional policies that can help reduce the observed differences, and by contributing to the development of the country as a whole. Consistent results were found with Verdoorn's Law by detecting increasing returns in the manufacturing industry, both by regions and by subsectors. The states that show lower Verdoon's coefficients (higher returns to scale) are definitely the ones that have grown the most.
\end{abstract}

Keywords: Verdoorn`s Law; Economic Growth; Productivity; Mexico

\section{INTRODUCTION}

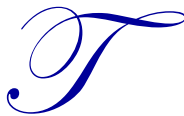

he heterogeneity observed in growth and development rates in the regions of Mexico is characterized by a very dynamic north region that has an industrial sector with high participation in the external sector; contrasting with a south region with a small industrial sector development. As result of this, it poses the need to determine what factors influence economic growth in order to propose regional policies that would help reduce the observed differences and to contribute to the development of the country as a whole. One of the relations that has been widely accepted as an explanation of the differences in growth rates between countries and regions, and considered by many as an alternative that allows us to reach an economic cumulative growth, are Kaldor's growth model which uses Myrdal's ideas as deciding factors in the process of economic growth and development, the Law of Verdoorn, and demand. Kaldor's growth model indicates that the main mechanisms that direct the process of cumulative growth are Verdoorn's Law that allows self-sustained growth, the dynamic increasing returns that contribute to the process of cumulative growth, and the initial conditions that are the deciding factors for the success or failure of the process. The importance of Verdoorn's Law is that it represents the basis of the models of economic growth of cumulative causation. With the introduction of a restriction of balance of payments, these models of economic growth have advanced on the explanation of the persistence of disparities in the growth rates in the developed economies. The law is also an important, though not indispensable, component of the approach of the demand orientated toward economic growth (McCombie and Ridder, 1984).

The most important conclusion of the model is that the differences on growth rates of an economy that operates in accordance to the free market logic without interventions can be kept and even increase, fundamentally, by the presence of increasing returns to scale (Kaldor, 1970; Thirlwall and Dixon; 1975; Harris and Lau; 1998).

In this paper, Verdoorn`s Law is used as an instrument for explaining the heterogeneity in growth rates for the states of Mexico for the period of 1985-2004 by supporting the hypothesis that the differences in growth rates 
between the states are explained by the specialization pattern. Such is the case that the industrialized states, whose productive structure is aimed at modern activities with higher returns to scale, show higher growth rates than those where the specialization is concentrated in the primary and manufacturing traditional type activities. The ordinary least square method and the panel data technique are used for estimating Verdoorn's coefficient for each one of the states of Mexico.

The results show consistency with Verdoorn's Law by finding increasing returns in the manufacturing industry by regions as well as by subsectors, and the states that definitely present smaller Verdoorn coefficients (higher returns to scale) are those that have grown the most. This is reflected by observing that the states with the higher weight of the manufacturing sector within its GDP grow more than those where the weight is smaller.

\section{ECONOMIC GROWTH THEORIES}

The debate about the economic growth and development revolves around the factors that influence the process. On the one hand, there is the neoclassic theory of economic growth which indicates that the free functioning of the market will generate a process of economic convergence; this process identifies as the reasons of economic growth and the explanation of its disparities such factors as supply, like the Robert Solow's model, as well as the recent contributions to this theory of Romer, Lucas, and Barro with the so called new growth theory. They try to explain the problem of divergence and whether growth is endogenous or exogenous. The importance of these reformulations lies in the fact that the new neoclassic theorists of growth have chosen the abandonment of essential assumptions such as the existence of perfect competition and the decreasing returns to scale of the factors.

On the other hand, there are those who consider demand as a deciding factor of economic growth, and from this point of view the classic development theory has its origins in the multiplier model of Harrod (1939) who developed a complete theoretical growth model. Rosenstein Rodan and his Big Push theory poses the need of a minimum investment that generates important opportunities of investment in other industries and becomes a deciding factor for achieving success in the process of economic development. He moves away from the basic assumptions of the traditional growth theory by proposing that the existence of increasing returns and exceeding labor force can generate multiple equilibriums; thus, depending on the initial conditions, the economy can be caught in a development trap (Ross, 2004). Another important contribution in the development theory is the one from Ragnar Nurkse (1953) who considers capital formation as the problem of countries that financially lag behind, and that are plunged in a circle of poverty that supposes a circular constellation of forces that tend to act and react one over the other in such a way that they keep the country in a state of poverty. The way of breaking up with this obstacle is by the expansion of the market and providing that the deciding factor of the magnitude of the market is productivity, there is the need of a widespread increase of productivity.

Myrdal's (1957) model of circular cumulative causation is located within the same line of thought, which explains the economic divergences observed among developed and underdeveloped countries as well as the tendency to expand these disagreements due to the circular cumulative causation process in the form of a "vicious circle." It refers to a cumulative causation in the sense that there is a circular interdependence principle between factors that are interrelated in a way that a change in one of them produces changes in the other ones in the same direction as the first change. The circular cumulative process can be ascending or descending, as the case may be. It recognizes the existence of backwashing and spread effects that act in the process of economic expansion.

This Myrdal's approach was refined and complemented by Kaldor (1950,1970) and Dixon and Thirlwall (1975) in their model the cumulative growth, which is generated by the increasing returns to scale contained in Verdoorn's Law that relates product growth with productivity growth. This is why a change in production creates increases in productivity, which diminishes the wages of efficiency and it generates an additional increase in production; thus, a new increase in productivity which brings a reinforced cumulative growth. One relevant aspect of Verdoom's Law is the fact that it proposes economic growth as endogenous through productivity growth; contrasting with neoclassic models where growth was determined exogenously. Kaldor's observation that the manufacturing sector is subject to increasing returns has been verified in several studies. 
This cumulative relation has appeared empirically and it happens mainly in the industrial sector due to the decrease of the unitary cost of production (or the increase of labor productivity) when the large-scale production expands followed by an increase in demand, or the positive relation between productivity growth rates of the job and the production growth rate called Verdoorn's Law, and to the price-elasticity of demand that brings about the expansion of demand beyond the reduction of the relative prices (Thirlwall, 1983).

\section{KALDOR-VERDOORN'S LAW}

The widely known Kaldor-Verdoorn's Law refers to the positive relation between production growth and productivity growth.

The basic Kaldor-Verdoorn's Law formula is:

$\mathrm{p}=\mathrm{a}+\mathrm{bq}$

$\mathrm{e}=\mathrm{c}+\mathrm{dq}$

Where, $\mathrm{q}, \mathrm{p}$, and e are the growth rates of production, productivity, and employment. Since productivity is equal to the product minus employment $(\mathrm{p}=\mathrm{q}-\mathrm{e})$, equation 2 is preferred to avoid the correlation between $\mathrm{p}$ and $\mathrm{q}$. Parameter $\mathrm{d}$ represents the productivity-production elasticity or Verdoorn's coefficient, being $0<\mathrm{d}<1$. This restriction for parameter d will be, according to Kaldor (1975), a sufficient condition for the presence of static and dynamic economies of scale, so that the relationship between e and q could be statistically significant.

A criticism of this specification is that it does not consider the contribution of capital for the increasing returns, but as Kaldor, Fingleton, and McCombie (1998) have argued this omission is not that serious if the capitalproduct ratio is assumed to be constant, which is valid for the developing countries since it has been empirically proven that the capital-product ratio is constant in the long run. This is the reason this equation is valid only for the economic system as a whole, and for the long term. Nevertheless, it is also argued that the capital-product ration shows an increasing trend in the developing countries, reason why a more appropriate specification for carrying out the sectorial analysis of Mexico must include k (Ocegueda, 2003).

For the short term and sectorial analysis, it is necessary to consider the influence of $\mathrm{k}$, this is why:

$\mathrm{e}=\pi+\gamma \mathrm{q}+\varphi \mathrm{k}$

Nevertheless, diverse empirical studies, among them Bairam (1987), have estimated this equation finding out that $\mathrm{k}$ is not statistically significant and that it presents an opposite sign, which it is explained with the fact that if there are demand restrictions for $\mathrm{k}$, it cannot be included as exogenous. So as the model proposes, the growth of capital stock is endogenous in the sense that is mainly determined by the production growth; then as Kennedy and Foley (1978) have suggested, a better specification of Verdoorn's Law is to use the total growth of the factors instead of employment as a dependent variable. In this way, both capital and employment growth work as functions of product growth. They specify the Verdoorn's Law as:

$\mathrm{f}=\delta+\theta \mathrm{q}$

Where $\mathrm{f}=\left(\alpha^{\prime} \mathrm{k}+\beta^{\prime} \mathrm{e}\right) \mathrm{y} \alpha^{\prime}+\beta^{\prime}=1$

$\mathrm{f}$ is the joint growth of the production factors. In this case, the coefficient $\theta$ is a reciprocal estimate of the degree of the returns to scale.

This equation is derived from the joint productivity of the factors represented by $p t=q-\left(a^{\prime} k+\beta{ }^{\prime} e\right)$, where $\alpha^{\prime}+\beta^{\prime}=1$ the weight of the factors. 


\section{ECONOMIC PERFORMANCE OF THE REGIONS OF MEXICO}

A problem that has distinguished Mexico is the enormous difference between the states; this fact has been illustrated and studied from different approaches. Some studies have shown that you can only observe convergence between the regions of Mexico in the period of 1940-1960, and it has been very slow to what one might expect due to the enormous observed differences; it has been pointed out that from this period on there has not been any evidence of convergence (Esquivel, 2000). This indicates that instead of the differences decreasing in growth among regions, they have remained or have had the tendency to increase. Velásquez (2003) states that the regional divergences in Mexico are part of a historical process and that the North American Free Trade Agreement has tended to perpetuate and increase the differences. Calderon (2005) suggests that the northern states have been the ones that have benefited from the opening and grew at the expense of other regions of the country, especially from the center and the south of Mexico, and were able to consolidate a specialization in certain areas of the industrial production.

The evidence has shown that the states that had a high concentration of industrial activities, like the northern and central regions, are those that have had a higher growth and are the ones that have benefited because of the commercial opening; while the regions with a less developed industrial sector, where the primary sector has been predominant, have tended to lag behind even more in the last years.

\section{DATA AND THE ESTIMATION METHOD}

The series of information of the manufacturing industry of the 32 States of Mexico for the gross added value, net fixed assets, and employment variables were obtained from INEGI's economic censuses for the period of 1980-2004. The data of the National and state GDP, as well as the Consumer Prices index, were obtained from the National Accounts System of INEGI.

The variables were deflated through the use of the consumer base national prices index $2000=100$, taken from the Center of Studies of Public Finance (CEFP).

Verdoorn's Law is estimated by the equation

$\mathrm{f}=\delta+\theta \mathrm{q}$

Where $\mathrm{f}=$ the rate of growth of the total factors for each of the states of the manufacturing industry. This variable was obtained by adding the total factors $f=w e+(1-w) k$, where $f$ is equal to the employment multiplied by $\mathrm{w}$ which corresponds to the participation of the employment of every state within the total employment, and the capital multiplied by (1-w). As an approximation of the capital stock, the growth rate of the variable net fixed assets was used. $\mathrm{q}=$ rate of growth of the gross added value in each of the states for the manufacturing industry.

\section{RESULTS}

In order to observe the type of returns that the manufacturing industry experiences in each of the above mentioned states, the results of the regressions using the growth of the total factor input as a dependent variable and the growth rate of the product as independent in the dynamic version of Kaldor Verdoorn's Law for the 32 states were used.

Most of the states show increasing returns in the manufacturing industry being congruent with Verdoorn's Law, but one can also see that the states with higher increasing returns are Chihuahua, Tamaulipas, Nuevo León, Coahuila, Baja California Sur, Quintana Roo, and Morelos. These are the ones that have grown at higher rates, and that states that show lower increasing returns are Colima, Campeche, Nayarit, Hidalgo, Sinaloa, and Yucatan; these are the ones that have tended to lag behind. In the estimations for the State of Mexico and the State of Oaxaca that show decreasing returns, the coefficients are less meaningful; thus, the result cannot be reliable and it is not an indicator of decreasing returns for those states. 
Figure 1: Results from Verdoorn's Law Estimate by State in Mexico

\begin{tabular}{|c|c|c|c|c|c|c|c|}
\hline State & $\Lambda$ & $\theta$ & $\mathbf{F}$ & $\mathbf{R}^{2}$ & D.W & $1 / \theta$ & Returns \\
\hline \multirow[t]{2}{*}{ Aguascalientes } & 2.58 & 0.7 & 9.04 & 0.36 & 2.12 & 1.43 & Increasing \\
\hline & $(0.46)$ & $(3.01)$ & & & & & \\
\hline \multirow[t]{2}{*}{ Baja California } & 1.43 & 1.1 & 66.83 & 0.66 & 2.11 & 0.91 & Decreasing \\
\hline & $(0.44)$ & $(8.18)$ & & & & & \\
\hline \multirow[t]{2}{*}{ Baja California Sur } & 0.53 & 0.53 & 5.89 & 0.16 & 2.95 & 1.89 & Increasing \\
\hline & $(0.08)$ & $(2.43)$ & & & & & \\
\hline \multirow[t]{2}{*}{ Campeche } & 1.4 & 0.74 & 26.3 & 0.48 & 2.15 & 1.35 & Increasing \\
\hline & $(0.37)$ & $(5.13)$ & & & & & \\
\hline \multirow[t]{2}{*}{ Coahuila } & -0.45 & 0.53 & 6.62 & 0.16 & 2.63 & 1.89 & Increasing \\
\hline & $(-0.16)$ & $(2.57)$ & & & & & \\
\hline \multirow[t]{2}{*}{ Colima } & 0.45 & 1.01 & 40.25 & 0.58 & 3.1 & 0.99 & Decreasing \\
\hline & $(0.11)$ & $(6.34)$ & & & & & \\
\hline \multirow[t]{2}{*}{ Chiapas } & 2.13 & 0.61 & 5.59 & 0.16 & 2.47 & 1.64 & Increasing \\
\hline & $(0.54)$ & $(2.36)$ & & & & & \\
\hline \multirow[t]{2}{*}{ Chihuahua } & -1.82 & 0.7 & 40.73 & 0.55 & 2.97 & 1.43 & Increasing \\
\hline & $(-0.7)$ & $(6.38)$ & & & & & \\
\hline \multirow[t]{2}{*}{ Distrito Federal } & -4.5 & 0.13 & 1.01 & 0.03 & 1.91 & 7.69 & Increasing \\
\hline & $(-2.47)$ & $(1.01)$ & & & & & \\
\hline \multirow[t]{2}{*}{ Durango } & -0.42 & 0.2 & 4.74 & 0.12 & 2.34 & 5.00 & Increasing \\
\hline & $(-0.13)$ & $(2.18)$ & & & & & \\
\hline \multirow[t]{2}{*}{ Guanajuato } & 1.95 & 0.5 & 12.93 & 0.28 & 2.06 & 2.00 & Increasing \\
\hline & $(0.84)$ & $(3.6)$ & & & & & \\
\hline \multirow[t]{2}{*}{ Guerrero } & 2.96 & 0.61 & 29.4 & 0.46 & 3 & 1.64 & Increasing \\
\hline & $(0.72)$ & $(5.42)$ & & & & & \\
\hline \multirow{2}{*}{ Hidalgo } & 1.68 & 0.36 & 5.26 & 0.13 & 2.78 & 2.78 & Increasing \\
\hline & $(0.43)$ & $(2.29)$ & & & & & \\
\hline \multirow[t]{2}{*}{ Jalisco } & -0.29 & 0.77 & 38.4 & 0.53 & 3.03 & 1.30 & Increasing \\
\hline & $(-0.170$ & $(6.2)$ & & & & & \\
\hline \multirow[t]{2}{*}{ México } & -2.06 & 0.51 & 17.31 & 0.34 & 2.66 & 1.96 & Increasing \\
\hline & $(-1.8)$ & $(4.16)$ & & & & & \\
\hline \multirow[t]{2}{*}{ Michoacán } & -0.28 & 0.36 & 2.92 & 0.1 & 1.5 & 2.78 & Increasing \\
\hline & $(-0.11)$ & $(1.71)$ & & & & & \\
\hline \multirow[t]{2}{*}{ Morelos } & 1.72 & -0.4 & 15.23 & 0.31 & 2.36 & -2.50 & Increasing \\
\hline & $(1.13)$ & $(-3.9)$ & & & & & \\
\hline \multirow[t]{2}{*}{ Nayarit } & 0.25 & 0.83 & 80.93 & 0.75 & 2.32 & 1.20 & Increasing \\
\hline & $(0.18)$ & (9) & & & & & \\
\hline \multirow[t]{2}{*}{ Nuevo León } & -0.7 & 0.94 & 14.47 & 0.3 & 2.81 & 1.06 & Increasing \\
\hline & $(-0.3)$ & $(3.8)$ & & & & & \\
\hline \multirow[t]{2}{*}{ Oaxaca } & 1.29 & 0.2 & 2.13 & 0.06 & 1.88 & 5.00 & Increasing \\
\hline & $(0.38)$ & $(1.46)$ & & & & & \\
\hline \multirow[t]{2}{*}{ Puebla } & 0.12 & 1 & 54.71 & 0.62 & 2.5 & 1.00 & Increasing \\
\hline & $(0.05)$ & $(7.4)$ & & & & & \\
\hline Querétaro & -0.95 & 0.34 & 13.1 & 0.28 & 2.88 & 2.94 & Increasing \\
\hline & $(-0.43)$ & $(3.62)$ & & & & & \\
\hline Quintana Roo & 2.81 & 0.5 & 17 & 0.37 & 2.11 & 2.00 & Increasing \\
\hline & $(0.93)$ & $(4.12)$ & & & & & \\
\hline San Luis Potosí & -2.27 & 0.64 & 81.58 & 0.71 & 2.94 & 1.56 & Increasing \\
\hline & $(-1.06)$ & $(9.03)$ & & & & & \\
\hline
\end{tabular}




\begin{tabular}{|l|c|c|c|c|c|c|c|}
\hline Sinaloa & 0.72 & 0.75 & 20.81 & 0.44 & 2.53 & 1.33 & Increasing \\
\hline & $(0.21)$ & $(4.98)$ & & & & & \\
\hline Sonora & 4.71 & 1.63 & 9.05 & 0.21 & 1.54 & 0.61 & Decreasing \\
\hline & $(0.57)$ & $(3.01)$ & & & & & \\
\hline Tabasco & 1.12 & 0.53 & 16.7 & 0.36 & 1.6 & 1.89 & Increasing \\
\hline Tamaulipas & $(0.52)$ & $(4.09)$ & & & & & \\
\hline & 3.9 & 0.34 & 7.51 & 0.18 & 3.1 & 2.94 & Increasing \\
\hline Tlaxcala & $(0.97)$ & $(2.74)$ & & & & & Increasing \\
\hline & 2.51 & 0.62 & 5.94 & 0.19 & 1.64 & 1.61 & \\
\hline Veracruz Llave & $(0.57)$ & $(2.44)$ & & & & & \\
\hline & 0.26 & 0.22 & 3.22 & 0.09 & 2.17 & 4.55 & Increasing \\
\hline Yucatán & $(0.14)$ & $(1.8)$ & & & & & \\
\hline & 1.64 & 0.49 & 14.97 & 0.31 & 2.36 & 2.04 & Increasing \\
\hline Zacatecas & $(0.55)$ & $(3.87)$ & & & & & Increasing \\
\hline
\end{tabular}

The importance of proving the validity of Verdoorn's Law, in other words, the positive relation between product growth and productivity, lies on identifying the types of returns that prevail in the manufacturing industry of the states of Mexico. This helps identify which states are the ones showing a higher degree of increasing returns, and to be able to take advantage of the positive effects that this has on economic growth by encouraging on getting advantages that allow a faster expansion of production and exploiting the economies of scale of their industrial sectors by favoring growth and the development of the country.

Another objective of this document is to estimate Verdoorn's Law at the level of subsectors by using the Panel Data. The use of this technique allows the observation of existing heterogeneity between the states and to identify the sectors with higher degree of increasing returns, and to relate them to the growth of the states. There are two procedures for estimating a data panel model: the model of fixed effects, which recognizes that the omitted variables can generate changes in the intercepts through time or among the transversal units, and the model of random effects, which tries to capture these differences through the random component of the model (Mayorga and Muñoz, 2000).

Figure 2. Results from Verdoorn's Law by Subsectors

\begin{tabular}{|c|c|c|c|c|c|c|}
\hline Subsector & $\Lambda$ & $\Theta$ & $\mathbf{F}$ & $\mathbf{R}^{2}$ & D. W. & $1 / \Theta$ \\
\hline \multirow[t]{2}{*}{31} & 0.25 & 0.29 & & -0.7 & 1.28 & 3.45 \\
\hline & $(0.48)$ & $(4.14)$ & & & & \\
\hline \multirow[t]{2}{*}{32} & & 0.53 & 2.42 & 0.45 & 3.14 & 1.89 \\
\hline & & $(6.29)$ & & & & . \\
\hline \multirow[t]{2}{*}{33} & -2.93 & 0.44 & & -0.82 & 1.08 & 2.27 \\
\hline & $(-4.80)$ & $(7.03)$ & & & & \\
\hline \multirow[t]{2}{*}{34} & 0.57 & 0.49 & & -0.6 & 1.42 & 2.04 \\
\hline & $(0.56)$ & $(5.13)$ & & & & \\
\hline \multirow[t]{2}{*}{35} & 1.79 & 0.53 & & -0.31 & 1.6 & 1.89 \\
\hline & $(1.43)$ & (6) & & & & \\
\hline \multirow[t]{2}{*}{36} & 0.05 & 0.57 & & -0.33 & 1.43 & 1.75 \\
\hline & $(0.04)$ & $(6.61)$ & & & & \\
\hline \multirow[t]{2}{*}{37} & 1.83 & 0.58 & & 0.24 & 2.1 & 1.72 \\
\hline & $(0.42)$ & $(5.02)$ & & & & \\
\hline \multirow[t]{2}{*}{38} & -0.66 & 0.63 & & -0.24 & 1.32 & 1.59 \\
\hline & $(-0.71)$ & $(7.03)$ & & & & \\
\hline \multirow[t]{2}{*}{39} & 6.30 & 0.66 & & -0.18 & 1.4 & 1.52 \\
\hline & $(2.17)$ & $(6.34)$ & & & & \\
\hline
\end{tabular}


According to Hausman's test, the method of fixed effects turned out to be suitable only for subsector 32, whereas the method of random effects was the appropriate one for all the rest of the subsectors.

Figure 2 shows the results of the estimated coefficients as well as some statistical ones: F, Durbin Watson, t- statistical. On the subsectors where the random effects method was used there is a constant because this method assumes that the individual effects are randomly distributed around a value, in this case the coefficient $\boldsymbol{\Lambda}$; whereas for subsector 32, where the fixed effects method was used, there is no constant because it is independent among the states, and thus there is a constant for each state. In order to identify what type of industries are included in each of the nine manufacturing subsectors, we briefly describe each of them as follows: subsector 31 , food products, drinks and tobacco; subsector 32, textiles, clothes and the leather industry; subsector 33, the wood industry and wood products (it includes furniture); subsector 34, paper and paper products, printing workshops and publishing houses; subsector 35, chemical substances, products derived from oil, coal, rubber, and plastic; subsector 36, non-metallic mineral products (it excludes the oil and coal derivatives); subsector 37, basic metallic industries; subsector 38, metallic products, machinery and equipment (it includes surgical instruments and precision equipment); and subsector 39, other manufacturing industries.

With the results obtained, we can determine that the sectors that have increasing returns are sectors 31,33 , 34,32 , and 35 . In order to compare if these are related, the subsector that presents higher increasing returns is subsector 31, and as we can see a great number of states are specialized in this subsector because all of them have a wide manufacturing participation on this subsector. Reason why we cannot just simply associate the GDP growth rates with specialization, rather it is the participation in the total manufacturing which influences the growth and the combination of several sectors with increasing returns. Subsector 33 is on second place as far as returns is concerned, which represents an important part in the participation of the states such as Durango, Quintana Roo, and Chihuahua. We can say that there is a positive relation between the participation of this subsector, increasing returns to scale, and the GDP growth rate.

\section{CONCLUSIONS}

According to the estimates, we can assure that the results are consistent with Verdoorn's Law. We found increasing returns in the manufacturing industry, both for regions and for subsectors, and most certainly the states that show lower coefficients of Verdoorn (higher increasing returns to scale) are the ones that have grown the most.

We were also able to detect those subsectors that show higher increasing returns through estimating Verdoorn's coefficient for every subsector by identifying the potential subsectors and their relation with growth. According to the results, we can conclude that the higher growth in the states is due to a higher participation in the manufacturing industry in general more than to specialization in subsectors with increasing returns. Though it is important to point out that the combination of specialization between subsector 31 and 38 shows a positive and very strong relation with the GDP growth rate in spite of the fact that subsector 31 shows increasing moderate returns, whereas subsector 38 is one with higher increasing returns; this is why it would be interesting to carry out a more disaggregated analysis, possibly at a secondary or product level that would be able to help determine clearly if specialization on some of these cases shows a strong positive effect on growth, and would allow us to suggest a specialization pattern.

The evidence found in this paper, and many others within the framework of cumulative growth models, suggests the need to foster industrial development in order to reduce differences between countries and regions, and to encourage economic growth. This is why the present challenge for governments is to implement regional policies that support the development of potential industries for achieving such purpose.

\section{AUTHOR INFORMATION}

Lourdes Alicia González Torres has a $\mathrm{PhD}$ in Economics. She is currently a professor, researcher, and coordinator of the PhD Program in Administrative Sciences at Universidad Autonoma de Baja California, Mexico. She is a candidate to the National Researchers' System (SNI). Scientific interests: Economic Growth and Development. E-mail: aliceinsky@yahoo.com (Corresponding author) 
Manuel Alejandro Ibarra Cisneros has a $\mathrm{PhD}$ in Industrial Economics and Labor Relations. He is currently a professor, researcher, and coordinator of the Graduate Program at Universidad Autonoma de Baja California, Mexico. He is a member of the National Researchers' System (SNI) Scientific interests: International Business and Labor Relations. E-mail: Maic781115@hotmail.com

Juan Manuel Ocegueda Hernández has a $\mathrm{PhD}$ in Economics. He is currently a professor and a researcher at Universidad Autonoma de Baja California, Mexico. He is a member of the National Researchers' System (SNI) level 2. Scientific interests: Economic Growth and Development. E-mail: jmocegueda@uabc.edu.mx

Karla Emilia Cervantes Collado has a $\mathrm{PhD}$ in Administrative Sciences. She is currently a professor, researcher, and coordinator of the Master's degree Program at Universidad Autonoma de Baja California, Mexico. Scientific interests: Management and Human Resources. E-mail: kkarla@uabc.edu.mx

\section{REFERENCES}

1. Lucas, R. Jr. (1988), “On the mechanic of Economic Developments”, Journal of Monetary Economics, XXII, pp.3-42.

2. $\quad$ MC. Combie J. S. L., Ridder J. R. (1984), “The Verdoorn Law Controversy: Some New Empirical Evidence Using U. S. States Data". Oxford Economic, Papers. New Series. Vol. 36 No. 2 pp. 268-284.

3. Myrdal, Gunnar (1957), "Teoría Económica y Regiones Subdesarrolladas" Fondo de Cultura Económica, México.

4. Nurkse, Ragnar (1953), "Problemas de Formación de Capital en los Países Insuficientemente Desarrollados" Fondo de Cultura Económica.

5. Ocegueda J. M. (2003), “Análisis Kaldoriano Del Crecimiento Económico De Los Estados De México 1980-2000", Comercio Exterior, Vol. 53, Num. 11, México, pp. 1024-1034.

6. Romer, Paul (1986), "Increasing returns and long run growth", Journal of Political Economy, October, 94:5, 1001- 1037.

7. Ros Jaime (2004), "La teoría del desarrollo y la economía del crecimiento", CIDE (Centro de Investigación y Docencia Económica) y FCE (Fondo de Cultura Económico), 2004

8. Solow Robert (1994), "Perspectives on growth Theory", Journal of economic perspectives, Vol 8, Num. 1, Winter, pp. 45-54.

9. Thirlwall A.P. (2000), "Trade agreement, trade liberalization and economic growth: a selective survey", A revised paper originally prepared for the African Development Report 2000. University of Kent at Canterbury, U.K.

10. Thirlwall A.P.(1983), “A plain man's guide to Kaldor's Law”, Journal of post Keynesian economics,345358.

11. Velázquez Flores R. (2003). "El impacto del TLCAN en el desarrollo regional de México: Una perspectiva comparada entre el norte y el sur-sureste".

12. Wohrle P, “A LeiKaldor-VerdoornNaEconomia Brasileira” CIP Sao Paulo Brasil Mayo 2002. 